\title{
The complex origins of domesticated crops in the Fertile Crescent
}

\author{
Terence A. Brown ${ }^{1}$, Martin K. Jones ${ }^{2}$, Wayne Powell ${ }^{3}$ and Robin G. Allaby ${ }^{4}$ \\ ${ }^{1}$ Faculty of Life Sciences, Manchester Interdisciplinary Biocentre, University of Manchester, Manchester M1 7DN, UK \\ ${ }^{2}$ Department of Archaeology, University of Cambridge, Cambridge CB2 3DZ, UK \\ ${ }^{3}$ Institute of Biological, Environmental and Rural Sciences, Aberystwyth University, Aberystwyth SY23 3DA, UK \\ ${ }^{4}$ University of Warwick, Wellesbourne, Warwickshire CV35 9EF, UK
}

\begin{abstract}
A combination of genetics and archaeology is revealing the complexity of the relationships between crop plants and their wild ancestors. Archaeobotanical studies are showing that acquisition of the full set of traits observed in domesticated cereals was a protracted process, intermediate stages being seen at early farming sites throughout the Fertile Crescent. New genetic data are confirming the multiregional nature of cereal domestication, correcting a previous view that each crop was domesticated by a rapid, unique and geographically localised process. Here we review the evidence that has prompted this reevaluation of the origins of domesticated crops in the Fertile Crescent and highlight the impact that this new multiregional model is having on modern breeding programmes.
\end{abstract}

\section{The importance of agriculture}

The beginning of agriculture around 10000 years ago has repeatedly been seen as the major transition in the human past, a changeover from the natural environment in control of humans, to humans in control of the natural environment. Before agriculture, humans were hunter-gatherers, dependent on wild resources for their nutritional requirements, which led to a largely nomadic lifestyle dictated by the annual cycle of animal and plant availability. The cultivation of plants and the husbandry of animals enabled humans to exert a measure of control over their food resources, protecting them from climatic and environmental uncertainty. As a result of further stabilisation and increase in the food supply, populations grew rapidly and the need for all members of a community to devote themselves to food procurement declined, leading to stratified societies and the elaborate civilisations and world systems of the historic period. Our present-day dependence on agriculture needs no emphasis: without it the world would support only a fraction of the current human population.

As such a key episode, it is no surprise that a diversity of research approaches has been applied to the study of agricultural origins. For archaeologists, agriculture is a central component in the cultural changes associated with the beginning of the Neolithic (see Glossary), with much of the recent focus on placing the domestication of plants in its correct context within the package of changes originally described by Gordon Childe as a 'revolution' [1] but now viewed as a series of distinct episodes occurring at different places at different times. Implicit in this debate has been a recognition that the transition to agriculture is itself a multi-episode process that begins with gathering from the wild and ends with the cultivation of plants that have undergone the full suite of genetic and phenotypic changes that characterise the domesticated crop [2,3]. Anthropologists, ecologists and evolutionists have proposed various models for the role of humans in this multi-episode process, these ranging from a view of agriculture as one of the inspired human inventions of the past [4] to hypotheses that define domestication as the outcome of a natural coevolutionary process driven by the predator-prey relationship between humans and edible plants $[5,6]$. And finally, but by no means least, geneticists have examined the diversity of modern crops to infer the genetic

\section{Glossary}

Amplified fragment length polymorphism (AFLP): a method involving selective amplification by PCR of restriction fragments from a digest of genomic DNA used to reveal DNA sequence variations between different members of a single species.

Archaeobotany: the subdiscipline of archaeology in which aspects of the human past are interpreted by examination of preserved plant remains.

cal BP: a radiocarbon date that has been calibrated against the radiocarbon content of tree rings to correct for the nonlinearity of the radiocarbon scale. A cal BP date is therefore equivalent to a historical date, with BP meaning 'years before 1950,' the latter being the year in which the radiocarbon convention was established.

Domestication: the outcome of a selection process that leads to plants adapted to cultivation and utilisation by humans.

Domestication syndrome: the set of traits that differ between the wild and domesticated versions of a crop species.

Fertile Crescent: the region of southwest Asia, comprising the valleys of the Tigris, Euphrates and Jordan rivers and their adjacent hilly flanks, where the earliest farming sites are located.

Gene flow: the transfer of alleles of a gene from one population to another, for example by cross-hybridisation (interbreeding).

Landrace: a locally adapted and distinct population of a crop, often genetically diverse, associated with traditional farming systems.

Monophyletic: refers to a group of organisms or DNA sequences that are derived from a single ancestral organism or DNA sequence.

Neolithic: the period of human cultural development characterised by adoption of a subsistence system based on agriculture.

Rachis: the component of the ear of a cereal plant to which the spikelets are attached prior to dehiscence.

Resequencing: identification of SNPs and other sequence variations within a species by sequencing entire genes or other genomic regions in multiple members of that species.

Single-nucleotide polymorphism (SNP): a point mutation that is carried by some individuals of a population.

Spikelet: the dispersal unit of grasses (including cereals), comprising a grain or grains and their adherent chaff fragments. According to the species, these chaff fragments might comprise pales, awns, glumes and attached rachis components. 
events accompanying plant domestication, both to address the human dimension to agricultural origins and to understand how the domestication process can be continued by modern breeding programmes aimed at further crop improvement.

There has always been cross-referral between the different parts of this rich tapestry of multidisciplinary research, but over the last few years different strands have begun to merge together in an excitingly synergistic fashion. Recent archaeological discoveries, described below, have emphasised that the first steps toward agriculture were being made hundreds if not thousands of years before fully domesticated crops appear in the archaeobotanical record, providing much greater depth to a transition that was once thought to have taken just a few human generations. Recognition of this increased timescale has been coincident with a greater appreciation of the complexity of the interplay between human selection and the evolution of the phenotypic traits associated with plant domestication. This emerging view of plant domestication as a protracted and biologically complex process has, until recently, been disputed by plant genetics, from which a paradigm more consistent with a rapid, highly localised transition emerged in the late 1990s and held sway over thinking for much of the succeeding decade. Now, however, the application of new genetic approaches is revealing patterns of diversity in modern crops that contradict this rapid transition model and bring the genetic evidence more in line with the protracted and complex process supported by archaeology and evolutionary biology. In this review, we examine the various lines of research that have led to this new picture of agricultural origins.

\section{The origins of agriculture in the Fertile Crescent}

Agriculture began independently in several parts of the world at about the same time [7], including Mesoamerica, where maize, the domesticated version of the wild grass teosinte, first appears, the Yangtze region of southeast Asia, where rice was first cultivated, and lowland and highland regions of South America, which are the sources of potato, peanut and manioc. The fourth major centre of domestication was the 'Fertile Crescent,' a region of southwest Asia comprising the valleys of the Tigris, Euphrates and Jordan rivers and their adjacent hilly flanks (Figure 1). The genetic studies which first established and then contradicted the rapid paradigm for the transition to agriculture have largely been carried out with crops that

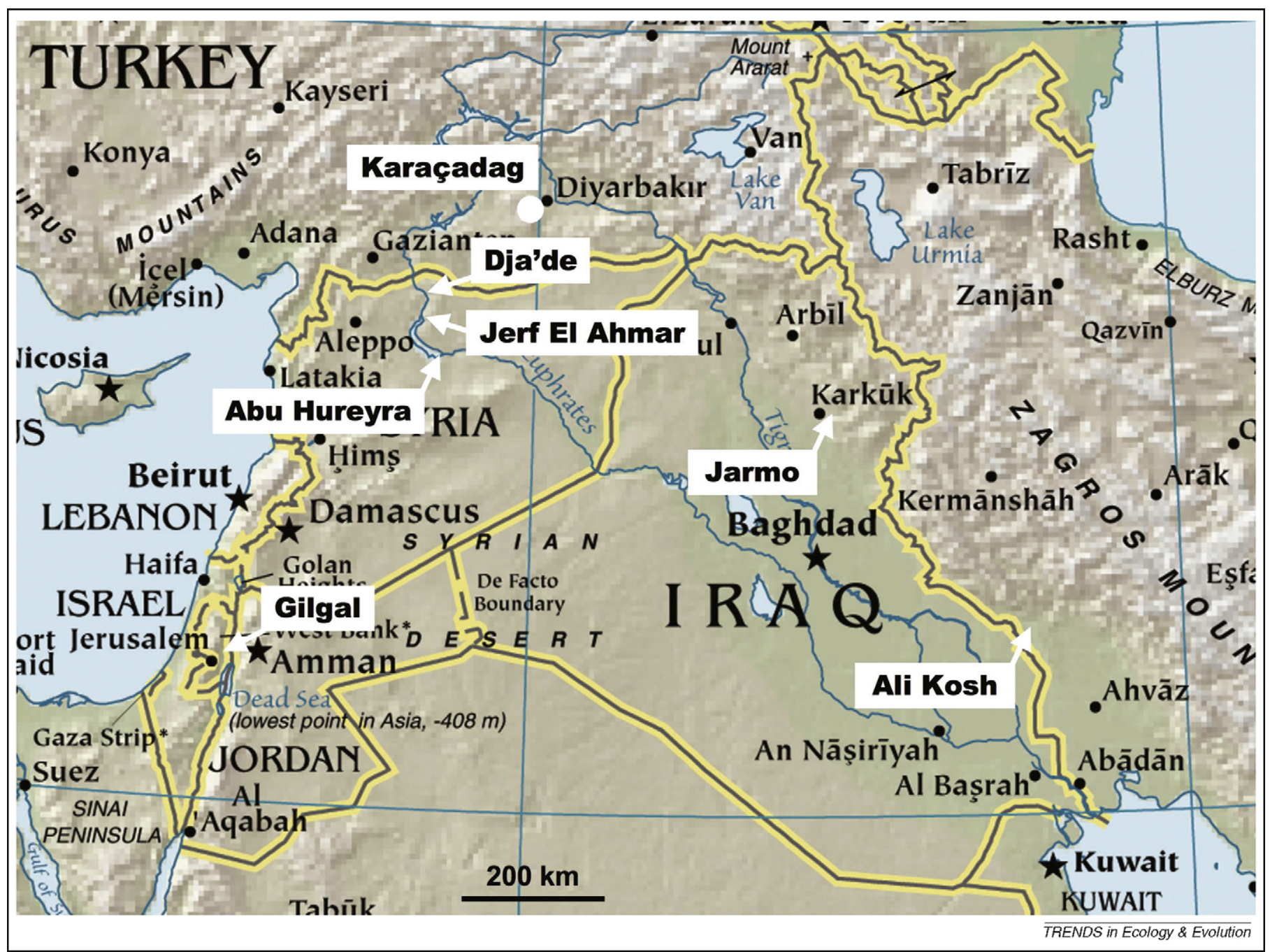

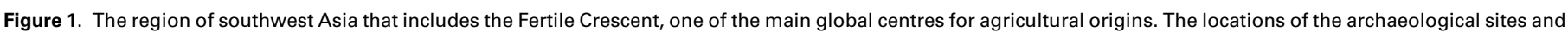
other important regions referred to in this review are shown. Map courtesy of the University of Texas Libraries, The University of Texas at Austin. 
originated in the Fertile Crescent, and this area is therefore the focus of this review.

Eight species are traditionally looked on as comprising the founder crops domesticated in the Fertile Crescent [8]. These are three cereals (diploid einkorn wheat [Triticum monococcum], tetraploid emmer wheat [T. dicoccum] and barley [Hordeum vulgare]), two pulses (lentil [Lens culinaris] and pea [Pisum sativum]), flax (Linum usitatissimum), bitter vetch (Vicia ervilia) and chickpea (Cicer arietinum). To this list could possibly be added faba bean (Vicia faba). The preserved remains of various combinations of these species are present at the earliest farming sites in the Fertile Crescent. Preservation is usually of grain and associated structures that have become burnt from mishaps during food processing or from destruction of grain stores. Often the resulting charred remains have undergone some structural distortion $[9,10]$, but usually not enough to prevent their identification. Importantly, the morphological features of charred specimens frequently retain indicators that enable a domesticated plant to be distinguished from its wild progenitor. With the cereals, for example, a characteristic feature of the domesticated type is that the ears are nonshattering, the spikelets (the dispersal propagules containing the grains) remaining

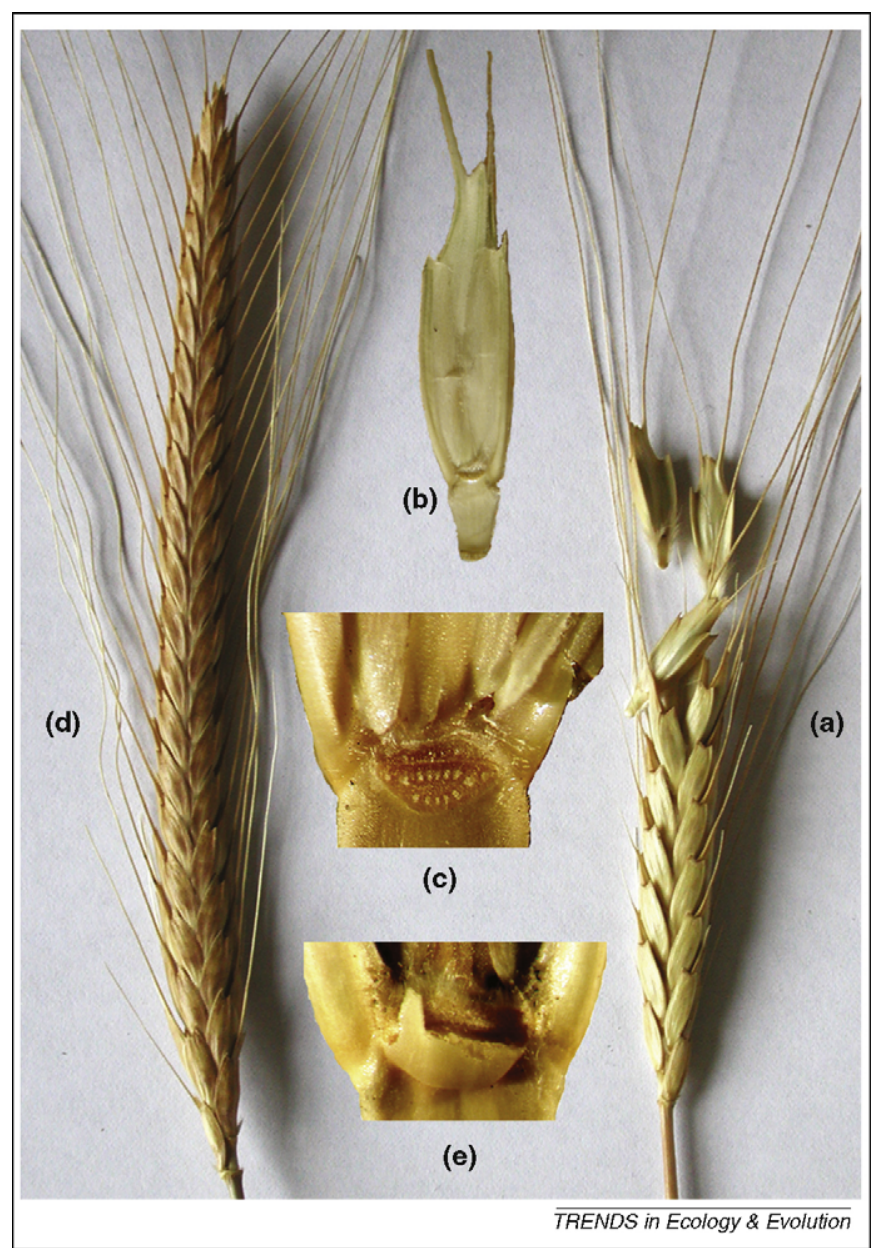

Figure 2. Morphological differences between the ears of wild and domestic wheat (a) The ears of wild einkorn shatter at maturity, (b) each spikelet leaving the stem as a dispersing propagule and (c) having at its base a smooth abscission scar. (d) By contrast, the ears of domesticated einkorn are nonshattering and remain intact after ripening, threshing being needed to detach the spikelets, which results in (e) a jagged break at the base of each one. From Ref. [19]. Reprinted with permission of AAAS.

\section{Box 1. The domestication syndrome of cultivated plants}

The domestication syndrome is the set of characters that distinguishes the crop plant from its wild ancestors [17,46-48]. The characters arise at least in part from human selection and hence relate to ways in which the plants are cultivated and harvested. For cereals, the domestication syndrome can be divided into seven components $[6,17]$ :

- Loss of seed dispersal, due to the tough rachis mutation which results in the grain remaining attached to the mature ear. This is often considered the most important domestication trait, as it makes propagation of the plant dependent on human intervention. For the farmer, the trait provides higher yields, as harvesting can be delayed until the grains have matured. Selection might be linked to use of sickles in early harvesting practises $[18,49]$.

- Loss of grain dispersal aids, such as hairs, hooks and awns, which facilitate wind and animal dispersive processes. This component of the domestication syndrome probably arises partly because the natural selection for grain dispersal aids is lost once the ear becomes nondehiscent, and partly from human selection for grain morphologies that simplify postharvest crop cleaning.

- Increase in grain size, which can arise by direct selection or via tillage, larger grain surviving deeper burial [46]. Grain size is often used as an indication of human intervention in plant reproduction.

- Loss of sensitivity to environmental cues for germination and flowering. The grains of most crops germinate soon after planting, whereas the wild versions often germinate only in response to environmental cues such as day length and temperature. This component of the domestication syndrome is thought to be selected by cultivators using grain from the previous harvest to sow the succeeding crop, as grain that germinates slowly will make a decreasing contribution to the harvested crop.

- Synchronous tillering and ripening. Again, this trait will be selected by cultivation practises, especially as these develop into a continuous annual cycle.

- Compact growth habit, selected by harvesting methods that preferentially sample plants of similar size and shape.

- Enhanced culinary chemistry, such as improved breadmaking quality of wheat [50] and changes to the sugar-starch balance in maize [51].

The domestication syndrome of non-cereal crops might exclude some of these traits but include others - such as reduction of defensive armour, an example being loss of spines from Dioscorea yams $[52,53]$, and reduction in defensive toxins, in yams and various legumes [6].

attached to the ear after ripening. Wild ears, by contrast, are dehiscent, shattering at maturity and releasing the detached spikelets. The nonshattering phenotype is determined by a mutation that causes a change in the nature of the rachis node, the structure that attaches the spikelet to the ear. The 'tough' rachis of a domesticated plant can be broken only by threshing, leaving a jagged break at the base of each spikelet, easily distinguished from the smooth abscission scar seen on a wild spikelet (Figure 2). The nonshattering phenotype is a central component of the 'domestication syndrome,' the suite of characters that distinguishes the cultivated version of a plant from its wild progenitor (Box 1).

Archaeological research is increasingly emphasising the complexity of the processes that preceded and accompanied emergence of the first domesticated crops [11,12]. The full suite of traits observed in modern domesticates arose from a variety of human interventions including specialisation in particular species, preparation of the soil, removal of weed competition, preference for larger grain, 
and active sowing and breeding. Advances in the study of grains, chaff and weed seeds from archaeological sites have enabled these different types of intervention and their distinct pathways to be recognised. Specialisation in particular species has been inferred at several sites. For example, at Gilgal in the Jordan Valley (see Figure 1), assemblages containing hundreds of thousands of wild barley and oat grains have been dated to $11400-11200$ cal BP [13] and, at Abu Hureyra on the Euphrates, wild rye with the first phenotypic indications of domestication was present around $12500 \mathrm{cal} \mathrm{BP}$ [14]. This was a period when the prevailing climatic conditions are thought to have been unsuitable for the unassisted establishment of these species, suggesting human intervention in the amelioration of the soil environment. Preparation of the soil can also be inferred from the ecological attributes of weed seeds recovered from several sites in the Upper Euphrates, where these weeds are found together with crop species that are still morphologically wild $[15,16]$. Preference for larger grains can also be directly measured in archaeological material. For example, barley grains recovered from Jerf el Ahmar and Dja'de became broader and thicker during 9800-9100 cal BP [16]. For several cereals, grain enlargement has a different chronology from rachis toughening, indicating that these two domestication traits did not evolve together [17]. The nature of the human selection acting on seed size could itself have been complex: smaller grains might be better adapted to areas with a short growing season, as smaller grains enable a faster maturation rate.

Archaeobotany therefore provides evidence that humans imposed different and possibly changing selective pressures on the plants being utilised, these activities occurring concurrently throughout a large region of the Fertile Crescent, the resulting evolutionary trajectories possibly coming together in complex ways. A linear sequence of events needs be envisaged only toward the end of the process, active sowing being a selective requirement for establishment of the tough rachis which, because it disables the natural dispersal mechanism, means the crop cannot survive without human intervention. Experiments have shown that under strong selection, rachis toughening can become established within 20-200 years [18], but the archaeobotanical evidence indicates a slower process, possibly taking 1000 years or more for einkorn wheat grown at sites in the Upper Euphrates [19]. As with all the special phenotypes of domesticated plants, the extent to which changes in rachis morphology resulted from conscious human selection is open to question.

\section{The genetic view of crop domestication}

It has long been recognised that genetic analysis of crop plants has the potential to provide valuable information on the origins of agriculture [20]. A modern crop is a relatively recent descendent from the wild populations from which it was derived and should preserve many of the genetic features of those populations. Hence, comparison between the genotypes of modern crop varieties and wild populations from throughout the natural range should indicate which wild populations are ancestral to the crop.

\section{Box 2. Genetic studies of agricultural origins}

Modern crops are relatively recent descendents of their wild ancestors, and although the genetic distance between the cultivated and wild versions is increased by the effects of human selection and the population bottleneck accompanying domestication, it is still necessary to type as many variable loci as possible to make meaningful studies of agricultural origins. Before the days of highthroughput DNA analysis, only limited progress was made in understanding the relationships between crops and wild plants simply because insufficient data could be obtained. One notable exception from the pre-DNA era was the monumental study by Barbara McClintock and colleagues of variations in the positions of heterochromatin knobs on maize chromosomes [54]. One of the conclusions drawn from these cytogenetic data was that maize was initially introduced into South America via the Andes.

The development of AFLP typing revolutionised studies of crop origins because it made possible the rapid generation of data from multiple lines of a crop. As well as its application to wheat and barley, AFLP typing has been used to examine the origins of the potato [55]. Microsatellites, the basis to human genetic profiling, have also been studied, for example in maize [56] and cassava [57]. More recently, the increasing amounts of genomic data becoming available have been utilised. Several genes responsible for domestication traits have been identified following the discovery of sequence-tagged sites (STS) to which they are closely linked. One method for STS discovery, used with barley, has been to sequence parts of the genome containing AFLPs associated with syndrome phenotypes [58], from which the single-nucleotide polymorphisms (SNP) responsible for the domestication traits are identified [59]. Expressed sequence tags (EST; DNA sequences derived from mRNAs) associated with domestication traits have also been discovered, leading to identification of seasonality genes in rice [60], and genes controlling fruit size and flowering time in sunflower [61]. Genomics is also providing rich data sets for phylogeographic studies of domestication. STS analysis has been used to study barley origins [34], and microsatellites derived from ESTs have allowed detailed histories to be constructed for less frequently studied crops such as finger millet and durum wheat [62-64]. Now genome databases are filling up with genome survey sequences (short sequenced segments of a genome), which are likely to provide new insights into the role in domestication of sequences not captured as ESTs.

This approach became feasible in the 1990s when the development of high-throughput methods made it possible to type multiple markers in many individual plants [21] (Box 2). Multilocus analysis was first applied to einkorn, possibly the first crop to undergo domestication, through typing of 288 amplified fragment length polymorphisms (AFLP) in 338 wild and cultivated accessions [22]. Phylogenetic trees constructed from the AFLP data showed that domesticated einkorn is monophyletic, all modern crop plants rooting back to a single point, indicative of their common descent from a single progenitor population of early domesticates. The early domesticates were genetically most similar to wild plants from the Karaçadag region of southeast Turkey, placing the location of einkorn domestication within this area. Similar AFLP analyses subsequently revealed single origins for both tetraploid wheat [23] and barley [24], the former also located in Karaçadag and the latter in the region of the modern Israel-Jordan border.

The first of these genetic studies was carried out before archaeology had fully revealed the complexity of the domestication process. Without this information, the strict monophyly and narrow geographical origins suggested by these studies was taken as strong evidence for a rapid, 
localised model for agricultural origins [25]. To take account of the growing archaeobotanical evidence showing that the transition to agriculture was a protracted, multiregional process, the model was subsequently revised by suggesting that the genetic analysis was accessing only the final stages of the domestication process. The monophyletic and localised event detected by AFLP typing was thus interpreted as emergence of a 'superior landrace' [26], possibly one possessing a major domestication phenotype such as the tough rachis [27]. It was argued that this scenario is compatible with a lengthy period of plant utilisation before domestication, but the difficulty remained that the tight affinity between each modern crop and a single wild population was consistent with a gradual transition only if during this transition the plants ancestral to the superior landrace either did not cross-hybridise with wild plants or only cross-hybridised with their parent population. Neither scenario is likely unless the early cultivators possessed the ability to isolate their crops from wild plants or if these pre-Neolithic communities were much less mobile than previously thought.

\section{New genetic approaches to the origins of domesticated crops}

The 'rapid, localised' paradigm remained in vogue despite its conflict with the archaeobotanical evidence, and even though computer simulations showed that the tree-building algorithms used to analyse multilocus data sets could not distinguish crops that are truly monophyletic from ones resulting from multiple independent domestications [28-30]. Eventually, genetic evidence challenging the monophyletic model began to appear, in particular for barley, the crop that, before the single-origin paradigm, had generally been considered to be the one most likely to have arisen from multiple domestications because of the presence of two different tough rachis mutations among modern landraces [31,32]. The first clear evidence that barley was domesticated more than once came from genotyping of chloroplast microsatellite markers [33] and resequencing of a region linked to the tough rachis locus [34], both studies indicating that barley landraces fall into at least two genetically distinct clusters, each with a different geographical origin. More extensive resequencing, of 18 loci containing 684 single-nucleotide polymorphisms (SNP), gave greater clarity [35], showing that barley was domesticated not only in the Israel-Jordan region but also in a region to the east of the Fertile Crescent, possibly in the western foothills of the Zagros mountains, where there are early farming sites at Ali Kosh and Jarmo (see Figure 1). This eastern domestication appears to have given rise to many of the landraces subsequently grown in central and east Asia [36]. New information is also emerging for einkorn, the crop whose AFLP analysis established the predominance of the single-origin paradigm, resequencing of 18 loci in 321 wild and 92 domesticated lines revealing a complex relationship between the cultivated and wild versions of the plant, indicative of a multitude of independent domestication events [37]. Similarly, with tetraploid wheat there is debate about the interpretation of the AFLP data [38] and whether these, and more recent data on chloroplast haplotypes [39] and restriction fragment length polymorphisms [40], indicate that there were at least two domestications.

These new genetic data are confirming that, as indicated by the archaeobotanical evidence, the processes leading to domestication were multiregional rather than highly localised events. Attention therefore becomes focussed on a new challenge: understanding the genetic events that led to fixation of the domestication traits. This is an exciting area of endeavour that will require account to be taken of the complexities of gene flow between the plants being utilised by humans and adjacent wild populations, the latter possibly changing if cultivators move, taking grain with them. The agricultural and natural environments provide selective pressures that frequently are opposed and which will draw plants down different evolutionary paths. For example, artificial sowing pressure will increase seed size but wild dispersal pressure will reduce it, and harvesting pressure favours the tough rachis whereas wild dispersal pressure favours the brittle version. The interaction between these conflicting pressures, mediated by gene flow, will be determined not only by the selective conditions in the agricultural and wild environments but also by the mode of inheritance and genetic control of the domestication traits. Most domestication traits exhibit complex patterns of inheritance and are influenced by both genetic and environmental factors. Recently, forward genetics approaches coupled with quantitative trait analysis have been successfully deployed to identify genes responsible for morphological changes associated with domestication [41]. Although the number of genes isolated is still relatively small, a theme appears to be emerging in which regulatory genes play the central role in development of the initial domestication syndrome whereas structural genes are important during subsequent selection for trait diversification [41]. Changes in the levels and patterns of gene expression are therefore likely to be important features associated with the domestication syndrome. Recent studies in Drosophila [42] have indicated that natural selection tends preferentially to influence the molecular mechanisms underlying regulatory variation, with cis-regulatory changes contributing greatly to divergence in interspecific gene expression patterns. Changes in regulatory rather than protein-coding regions might also reduce the pleiotropic effects of the genetic events occurring during domestication. Our gradually increasing knowledge of the genes underlying the domestication syndrome is therefore providing an experimental framework for testing new hypotheses that sit at the interface between plant genetics and archaeology.

\section{Concluding remarks}

We have moved from a position where the attention of geneticists was focussed on a simplistic model for agricultural origins to one where genetics and archaeobotany are combining to understand the evolutionary events that led to the emergence of domesticated crops (Figure 3). These studies are not just arcane investigations into past events. In many respects, the domestication process did not end 10000 years ago. Crops have undergone continual evolutionary change resulting in their gradual improvement as nutritional resources. An example is provided by our recent 


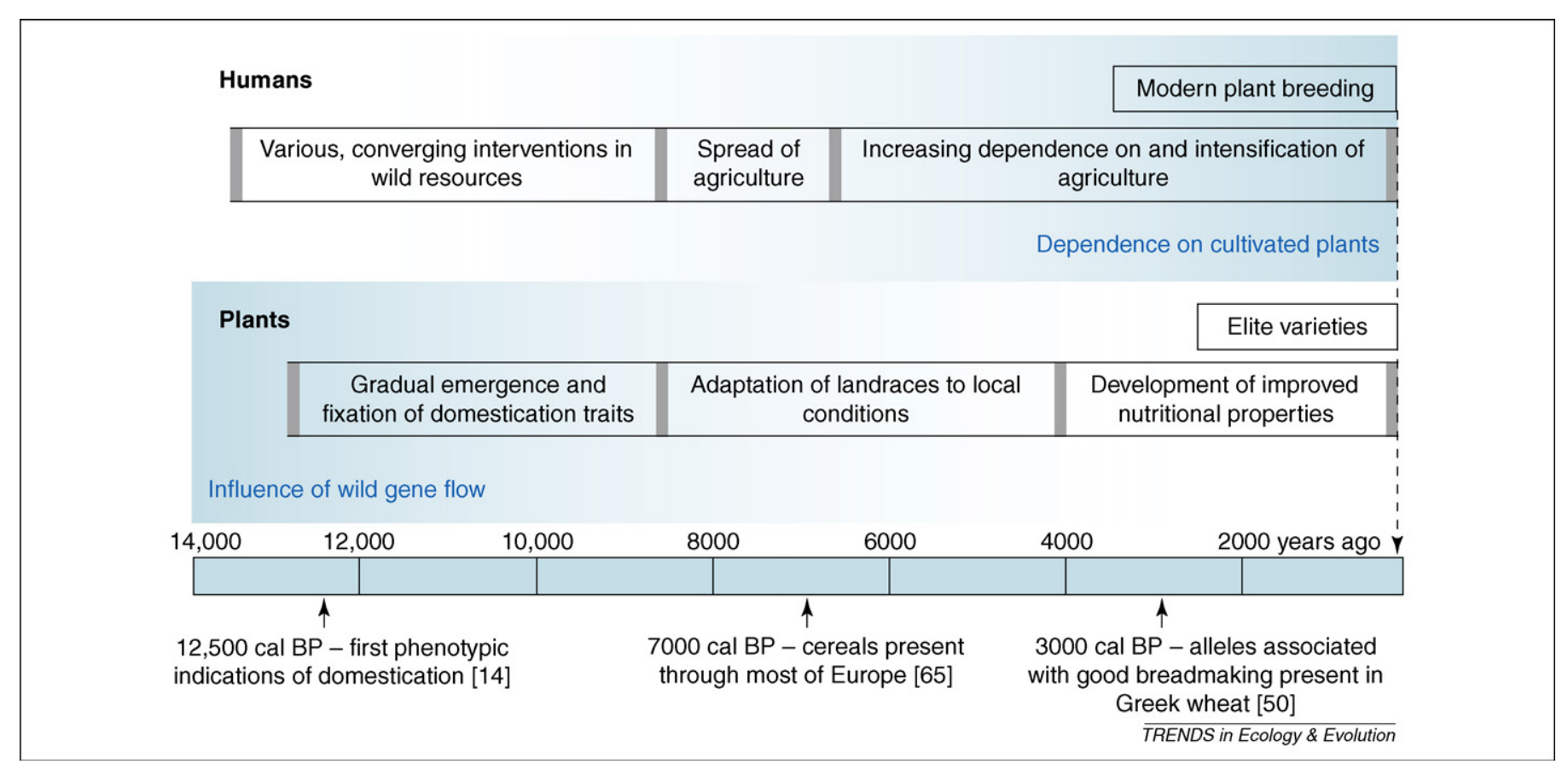

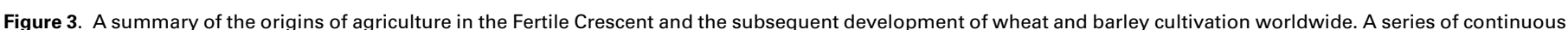

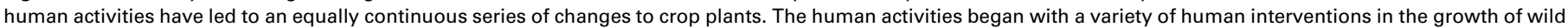
plants, probably beginning over 13000 cal BP $[11,12]$. These interventions prompted the gradual emergence of domestication traits in the crop plants, the first indications of these traits being seen in the archaeobotanical record around $12500 \mathrm{cal}$ BP [14]. Eventual fixation of the domestication syndrome by $\sim 9000$ cal BP enabled agriculture to spread beyond its area of origin to other parts of southwest Asia and throughout Europe, north Africa and south-central regions of Asia [17,65]. The spread of agriculture

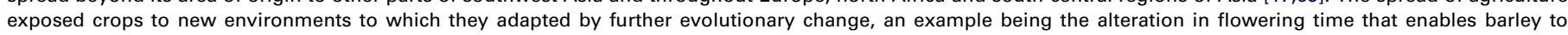

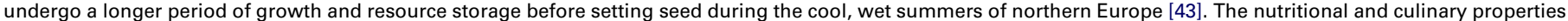
of locally adapted landraces also underwent change as agriculture gradually intensified, ancient DNA analysis suggesting that glutenin alleles associated with good

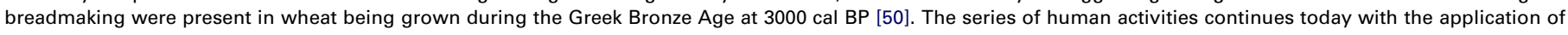
directed breeding programmes which have resulted in the elite varieties of cereals that support our modern society.

work which suggests that a mutation of the photoperiod 1 gene that alters the flowering time of barley, enabling plants to grow more successfully in the cool, wet climate of northern Europe, originated in a small number of wild populations in Iran and entered the cultivated gene pool some time after the establishment of the domesticated crop [43]. Further studies of the domestication process coupled with modern genomics approaches provide the opportunity to identify other genes responsible for adaptation to changing environments [44]. We should view the first attempts by humans to manage their wild plant resources as the initial step on a lengthy and unbroken path that continues today with our scientifically informed programmes of crop improvement. Our efforts will be more dependent in the future on accessing natural sources of biodiversity that harbour mutations that have been selected over evolutionary time for adaptation to new environments [45]. An understanding of the genetic events occurring during domestication will therefore help us design knowledge-based breeding programmes that will enable the full genetic potential of the wild and cultivated gene pools to be harnessed for the benefit of society.

\section{Acknowledgements}

We thank George Willcox for providing the artwork for Figure 2. We also thank the Natural Environment Research Council for supporting our work on the origins of agriculture.

\section{References}

1 Childe, V.G. (1928) The Most Ancient East: The Oriental Prelude to European Prehistory. Kegan Paul
2 Harris, D.R. (1989) An evolutionary continuum of people-plant interaction. In Foraging and Farming: The Evolution of Plant Exploitation (Harris, D.R. and Hillman, G.C., eds), pp. 11-26, Routledge

3 Harris, D.R. (1996) Introduction: themes and concepts in the study of early agriculture. In The Origins and Spread of Agriculture and Pastoralism in Eurasia (Harris, D.R., ed.), pp. 1-9, UCL Press

4 Diamond, J. (1997) Guns, Germs and Steel. Random House

5 Rindos, D. (1984) The Origins of Agriculture: An Evolutionary Perspective. Academic Press

6 Jones, M.K. and Brown, T.A. (2007) Selection, cultivation and reproductive isolation: a reconsideration of the morphological and molecular signals of domestication. In Rethinking Agriculture: Archaeological and Ethnoarchaeological Perspectives (Denham, T. et al., eds), pp. 36-49, Left Coast Press

7 Gepts, P. (2004) Crop domestication as a long-term selection experiment. Plant Breed. Rev. 24, 1-44

8 Zohary, D. (1996) The mode of domestication of the founder crops of Southwest Asian agriculture. In The Origins and Spread of Agriculture and Pastoralism in Eurasia (Harris, D.R., ed.), pp. 142-158, UCL Press

9 Braadbaart, F. and van Bergen, P.F. (2005) Digital imaging analysis of size and shape of wheat and pea upon heating under anoxic conditions as a function of temperature. Veget. Hist. Archaeobot. 14, 67-75

10 Threadgold, J. and Brown, T.A. (2003) Degradation of DNA in artificially charred wheat seeds. J. Archaeol. Sci. 30, 1067-1076

11 Balter, M. (2007) Seeking agriculture's ancient roots. Science 316, 1830-1835

12 Willcox, G. (2005) The distribution, natural habitats and availability of wild cereals in relation to their domestication in the Near East: multiple events, multiple centres. Veget. Hist. Archaeobot. 14, 534-541

13 Weiss, E. et al. (2006) Autonomous cultivation before domestication. Science 312, 1608-1611

14 Hillman, G.C. et al. (2001) New evidence of Lateglacial cereal cultivation at Abu Hureyra on the Euphrates. Holocene 11, 383-393

15 Colledge, S. (1998) Identifying pre-domestication cultivation using multivariate analysis. In The Origins of Agriculture and Crop 
Domestication (Damania, A.R. et al., eds), pp. 121-131, International Centre for Agricultural Research in the Dry Areas

16 Willcox, G. et al. (2008) Early Holocene cultivation before domestication in northern Syria. Veget. Hist. Archaeobot. 17, 313325

17 Fuller, D.Q. (2007) Contrasting patterns in crop domestication and domestication rates: recent archaeological insights from the Old World. Ann. Bot. (Lond.) 100, 903-924

18 Hillman, G. and Davies, M.S. (1990) Domestication rates in wild wheats and barley under primitive cultivation. Biol. J. Linn. Soc. 39, 39-78

19 Tanno, K-I. and Willcox, G. (2006) How fast was wild wheat domesticated? Science 311, 1886

20 Jones, M.K. and Brown, T.A. (2000) Agricultural origins: the evidence of modern and ancient DNA. Holocene 10, 775-782

21 Vos, P. et al. (1995) AFLP: a new technique for DNA fingerprinting. Nucleic Acids Res. 23, 4407-4414

22 Heun, M. et al. (1997) Site of einkorn wheat domestication identified by DNA fingerprinting. Science 278, 1312-1314

23 Özkan, H. et al. (2002) AFLP analysis of a collection of tetraploid wheats indicates the origin of emmer and hard wheat in southeast Turkey. Mol. Biol. Evol. 19, 1797-1801

$24 \mathrm{Badr}$, A. et al. (2000) On the origin and domestication history of barley. Mol. Biol. Evol. 17, 499-510

25 Diamond, J. (1997) Location, location, location: the first farmers. Science 278, 1243-1244

26 Salamini, F. et al. (2002) Genetics and geography of wild cereal domestication in the Near East. Nat. Rev. Genet. 3, 429-441

27 Abbo, S. et al. (2006) The ripples of "The Big (agricultural) Bang": the spread of early wheat cultivation. Genome 49, 861-863

28 Allaby, R.G. and Brown, T.A. (2003) AFLP and the origins of domesticated crops. Genome 46, 448-453

29 Reeves, P.A. and Richards, C.M. (2007) Distinguishing terminal monophyletic groups from reticulate taxa: performance of phenetic, tree-based, and network procedures. Syst. Biol. 56, 302-320

30 Allaby, R.G. et al. (2008) The genetic expectations of a protracted model for the origins of domesticated crops. Proc. Natl. Acad. Sci. U. S. A. 105, 13982-13986

31 Takahashi, R. (1972) Non brittle rachis 1 and non brittle rachis 2. Barley Genet. Newsl. 2, 181-182

32 Zohary, D. (1999) Monophyletic vs polyphyletic origin of crops found in the Near East. Genet. Resour. Crop Evol. 46, 133-142

33 Molina-Cano, J.L. et al. (2005) Chloroplast DNA microsatellite analysis supports a polyphyletic origin for barley. Theor. Appl. Genet. 110, 613619

34 Azhaguvel, P. and Komatsuda, T. (2007) A phylogenetic analysis based on nucleotide sequence of a marker linked to the brittle rachis locus indicates a diphyletic origin of barley. Ann. Bot. (Lond.) 100, 1009-1015

35 Morrell, P.L. and Clegg, M.T. (2007) Evidence for a second domestication of barley (Hordeum vulgare) east of the Fertile Crescent. Proc. Natl. Acad. Sci. U. S. A. 104, 3289-3294

36 Saisho, D. and Purugganan, M.D. (2007) Molecular phylogeography of domesticated barley traces expansion of agriculture in the Old World. Genetics 177, 1765-1776

37 Kilian, B. et al. (2007) Molecular diversity at 18 loci in 321 wild and 92 domesticate lines reveal no reduction of nucleotide diversity during Triticum monococcum (einkorn) domestication: implications for the origins of agriculture. Mol. Biol. Evol. 24, 2657-2668

38 Özkan, H. et al. (2005) A reconsideration of the domestication geography of tetraploid wheat. Theor. Appl. Genet. 110, 1052-1060

39 Mori, N. et al. (2003) Origins of domesticated emmer and common wheat inferred from chloroplast DNA fingerprinting. In Proceedings of the 10th International Wheat Genetics Symposium, Paestum, Italy (Pogna, N.E. et al., eds), pp. 25-28, Instituto Sperimentale per la Cerealicoltura
40 Luo, M-C. et al. (2007) The structure of wild and domesticated emmer wheat populations, gene flow between them, and the site of emmer domestication. Theor. Appl. Genet. 114, 947-959

41 Doebley, J.F. et al. (2006) The molecular genetics of crop domestication. Cell 127, 1309-1321

42 Wittkopp, P.J. et al. (2008) Regulatory changes underlying expression differences within and between Drosophila species. Nat. Genet. 40, $346-350$

43 Jones, H. et al. (2008) Population based re-sequencing reveals that the flowering time adaptation of cultivated barley originated east of the Fertile Crescent. Mol. Biol. Evol. 25, 2211-2219

44 Ross-Ibarra, J. et al. (2007) Plant domestication, a unique opportunity to identify the genetic basis of adaptation. Proc. Natl. Acad. Sci. U. S. A. $104,8641-8643$

45 Zamir,D. (2008) Plant breeders go back to nature. Nat. Genet. 40,269-272

46 Harlan, J.R. and De Wet, J.M.J. (1973) Comparative evolution of cereals. Evolution Int. J. Org. Evolution 27, 311-325

47 Hawkes, J.G. (1983) The Diversity of Crop Plants. Harvard University Press

48 Zohary, D. and Hopf, M. (2000) Domestication of Plants in the Old World. (3rd edn), Oxford University Press

49 Bar-Yosef, O. (1998) The Natufian culture in the Levant. Evol. Anthropol. 6, 159-177

50 Brown, T.A. (1999) How ancient DNA may help in understanding the origin and spread of agriculture. Philos. Trans. R. Soc. Lond. B Biol. Sci. 354, 89-98

51 Jaenicke-Després, V. et al. (2003) Early allelic selection in maize as revealed by ancient DNA. Science 302, 1206-1208

52 Mignouna, H.D. and Dansi, A. (2003) Yam (Dioscorea ssp.) domestication by the Nago and Fon ethnic groups in Benin. Genet. Resour. Crop Evol. 50, 519-528

53 Vernier, P. et al. (2003) Studies on yam domestication and farmers' practices in Benin and Nigeria. Outlook Agric. 32, 35-41

54 McClintock, B. et al. (1981) Chromosome Constitution of the Races of Maize: Its Significance in the Interpretation of Relationships between Races and Varieties in the Americas. Colegio de Postgraduados, (Chapingo)

55 Spooner, D.M. et al. (2005) A single domestication for potato based on multilocus amplified fragment length polymorphism genotyping. Proc. Natl. Acad. Sci. U. S. A. 102, 14694-14699

56 Matsuoka, Y. et al. (2002) A single domestication for maize shown by multilocus microsatellite genotyping. Proc. Natl. Acad. Sci. U. S. A. 99, 6080-6084

57 Olsen, K.M. and Schall, B.A. (2001) Microsatellite variation in cassava (Manihot esculenta, Euphorbiaceae) and its wild relatives: further evidence for a southern Amazonian origin of domestication. Am. J. Bot. 88, 131-142

58 Komatsuda, T. et al. (1998) Development of STS markers closely linked to the vrs1 locus in barley, Hordeum vulgare. Genome 41, 680-685

59 Komatsuda, T. et al. (2007) Six-rowed barley originated from a mutation in a homeodomain-leucine zipper I-class homeobox gene. Proc. Natl. Acad. Sci. U. S. A. 104, 1424-1429

60 Xue, W. et al. (2008) Natural variation in Gdh7 is an important regulator of heading date and yield potential in rice. Nat. Genet. 40, 761-767

61 Lai, Z. et al. (2005) Identification and mapping of SNPs from ESTs in sunflower. Theor. Appl. Genet. 111, 1532-1544

62 Dida, M.M. et al. (2006) The genetic map of finger millet Eleusine coracana. Theor. Appl. Genet. 114, 321-332

63 Dida, M.M. et al. (2008) Population structure and diversity in finger millet (Eleusine coracana) germplasm. Trop. Plant Biol. 1, 131-141

64 Chabane, K. et al. (2008) Generation and exploitation of EST-derived SSR markers for assaying molecular diversity in durum wheat populations. Genet. Resour. Crop Evol. 55, 869-881

65 Price, T.D. (ed.) (2000) Europe's First Farmers, Cambridge University Press 